\title{
Cytokine inflammatory threat, but not LPS one, shortens GABAergic synaptic currents in the mouse spinal cord organotypic cultures
}

\author{
Vincenzo Giacco ${ }^{1,5}$, Giulia Panattoni ${ }^{1}$, Manuela Medelin², Elena Bonechi ${ }^{3}$, Alessandra Aldinucci ${ }^{3}$, \\ Clara Ballerini ${ }^{4^{*}}$ and Laura Ballerini ${ }^{1 *}$ (D)
}

\begin{abstract}
Background: Synaptic dysfunction, named synaptopathy, due to inflammatory status of the central nervous system (CNS) is a recognized factor potentially underlying both motor and cognitive dysfunctions in neurodegenerative diseases. To gain knowledge on the mechanistic interplay between local inflammation and synapse changes, we compared two diverse inflammatory paradigms, a cytokine cocktail (CKs; IL-1 $\beta$, TNF-a, and GM-CSF) and LPS, and their ability to tune GABAergic current duration in spinal cord cultured circuits.

Methods: We exploit spinal organotypic cultures, single-cell electrophysiology, immunocytochemistry, and confocal microscopy to explore synaptic currents and resident neuroglia reactivity upon CK or LPS incubation.

Results: Local inflammation in slice cultures induced by CK or LPS stimulations boosts network activity; however, only CKs specifically reduced GABAergic current duration. We pharmacologically investigated the contribution of $G_{A B A_{A}} R$ a-subunits and suggested that a switch of $G A B A_{A} R$ a1-subunit might have induced faster $G A B A_{A} R$ decay time, weakening the inhibitory transmission.
\end{abstract}

Conclusions: Lower GABAergic current duration could contribute to providing an aberrant excitatory transmission critical for pre-motor circuit tasks and represent a specific feature of a CK cocktail able to mimic an inflammatory reaction that spreads in the CNS. Our results describe a selective mechanism that could be triggered during specific inflammatory stress.

Keywords: Organotypic spinal slices, Patch-clamp, Synaptic currents, Neuroinflammation, GABAergic inhibition, GABAergic receptors, Spinal circuits, NKCC1, Resident neuroglia

\section{Background}

Neuroinflammation is a characterizing trait of various central nervous system (CNS) pathologies, from neurodegenerative diseases to neuropsychiatric disorders [1]. Currently, intense research efforts are dedicated to the understanding of how the different signaling pathways, activated in neurons and neuroglia by the inflammatory milieus, may ultimately promote synaptic dysfunction

\footnotetext{
* Correspondence: clara.ballerini@unifi.it; laura.ballerini@sissa.it ${ }^{4}$ Dipartimento di Medicina Sperimentale e Clinica, University of Florence, 50139 Florence, Italy

${ }^{1}$ International School for Advanced Studies (SISSA/ISAS), 34136 Trieste, Italy Full list of author information is available at the end of the article
}

[2-4]. For example, several studies documented, in the interplay between the immune system and neuronal function, the involvement of pro-inflammatory cytokines (CKs), such as TNF- $\alpha$, IL-1 $\beta$, and IL-6 [5-7]. Similarly, lipopolysaccharide (LPS, an endotoxin derived from gramnegative bacteria)-induced neuroinflammation may lead to synaptic dysfunctional signaling contributing significantly to cognitive disturbances [8]. In contrast to the general agreement on the emergence of synaptopathy due to inflammation [2], the rules governing the specific neurotransmission systems involved, and their tuning, are unclear. Conflicting evidence indicate that exogenous CK applications may increase [9] or decrease [10] glutamatergic

(c) The Author(s). 2019 Open Access This article is distributed under the terms of the Creative Commons Attribution 4.0 International License (http://creativecommons.org/licenses/by/4.0/), which permits unrestricted use, distribution, and 
synaptic transmission, as well as for GABAergic transmission, where both decreases $[11,12]$ and increases $[13,14]$ are reported.

With the aim of dissecting the impact of immune status alterations on neural circuit function, we focused our study on the effects of local inflammation in a controlled micro-environment where neurons and neuroglial cells maintain appropriate organization: the organotypic slice cultures developed from the embryonic mouse spinal cord. In this complex in vitro model, the sensory-motor cytoarchitecture, synaptic properties, and spinal cord resident cells are retained in a 3D-fashion [15-17]. By the use of this model, we preliminarily reported the emergence of synaptopathy in pre-motor circuits following CK transient exposure, characterized by a speeding up of the decay phase of GABAergic inhibitory currents [17]. A broader question is to what extent the tuning of GABAergic current duration may occur as a response to any local alteration in the inflammatory status of the spinal cord, disrupting physiological excitability levels, being GABAergic neurotransmission an important determinant of spinal circuit coordination [18].

In the present study, we compare the effects on synaptic transmission of different experimental inflammatory models, LPS, a potent trigger of cytokine induction $[19,20]$ and the most common stimulus used to investigate microglial reactivity in brain inflammation, and a pro-inflammatory cocktail containing interleukin- $1 \beta$ (IL-1ß), well-known determinant of neuropathy $[1,2]$, tumor necrosis factor $\alpha$ (TNF- $\alpha)$, present during Th1/ Th17-mediated inflammatory reactions, and granulocyte macrophage-colony stimulating factor (GM-CSF), targeting resident microglial cells. These cytokines are key factors known to affect neuronal functions and responsible for pro-inflammatory effects in the CNS of multiple sclerosis animal models [21]. We adopted relatively acute treatments (hours), known to trigger inflammatory responses, without inducing direct neurotoxicity, yet still able to alter synaptic transmission [17]. Thus, organotypic spinal cord cultures were transiently exposed to pro-inflammatory CK cocktail (TNF- $\alpha$, IL-1 $\beta$, and GM-CSF, 4 and $6 \mathrm{~h}$; [17]) or to LPS $(4,6$, and $24 \mathrm{~h})$.

To compare CKs and LPS impact on synaptic activity, in particular on GABAergic currents, we used single-cell patch-clamp recordings. We further explore by immunofluorescence and confocal microscopy resident neuroglia reactivity, and we measure the local production of cytokines and chemokines in response to the two inflammatory stresses. CKs and LPS significantly increase the generation of these signaling proteins, and both danger signals boost basal synaptic activity, inducing a distinct transformation of resident neuroglia morphology. To note, only CKs promote changes in inhibitory transmission time course. Finally, we investigated the mechanisms responsible for the shortening of GABAergic current duration upon CK treatment, since these may emerge as potential targets for novel therapeutics.

\section{Methods \\ Organotypic spinal cord cultures, pro-inflammatory treatments, and pharmacology}

All experiments were performed in accordance with the EU guidelines (2010/63/UE) and Italian law (Decree 26/14) and were approved by the local authority veterinary service and by our institution (SISSA) ethical committee. All efforts were made to minimize animal suffering and to reduce the number of animals used. Animal use was approved by the Italian Ministry of Health, in agreement with the EU Recommendation 2007/526/CE.

Organotypic spinal cord and dorsal root ganglia (DRG) slices were obtained from mouse embryos (C57BL/6 J) at E12-13 of gestation as previously described $[15-17,22]$. Briefly, pregnant mice were sacrificed by $\mathrm{CO}_{2}$ overdose and fetuses delivered by cesarean section. Isolated fetuses were decapitated, and their backs were isolated from low thoracic and high lumbar regions and transversely sliced $(275 \mu \mathrm{m})$ with a tissue chopper. After dissecting the spinal cord slices and the DRG from the surrounding tissue, slices were embedded into a thick matrix obtained by chicken plasma (Rockland) and thrombin (Sigma) clot. Slices were cultured in plastic tubes with $1 \mathrm{~mL}$ medium. The tubes were kept in a roller drum rotating 120 times per hour in an incubator at $37^{\circ} \mathrm{C}$ in the presence of humidified atmosphere, with $5 \% \mathrm{CO}_{2}$. Experiments were performed on spinal cultures at 14-21 days in vitro (DIV). The day of the experiment, organotypic slices were incubated with standard medium (control) or, for 4 or $6 \mathrm{~h}(4 \mathrm{H}$ and $6 \mathrm{H})$, with two different inflammatory paradigms: (i) a cocktail of the mouse recombinant cytokines $(10 \mathrm{ng} / \mathrm{mL}$ each) TNF- $\alpha$ (R\&D Systems, \#210-TA/CF), IL-1 $($ R\&D Systems, \#M15330), and granulocyte-macrophage colony-stimulating factor (GMCSF; R\&D Systems, \#P04141; [17, 23]); (ii) lipopolysaccharide (LPS; $1 \mu \mathrm{g} / \mathrm{mL}$, Sigma, O55:B5). For LPS, we also tested a longer incubation time point $(24 \mathrm{H})$. CKs or LPS were removed after the incubation times, prior to electrophysiological recordings.

Bumetanide (Sigma) was diluted in phosphate buffer solution (PBS $1 \times$, Sigma) and used to block the $\mathrm{Na}^{+} / \mathrm{K}^{+} /$ $\mathrm{Cl}^{-}$co-transporter (NKCC1; [24]). To decrease the cytoplasmic chloride concentration, slices were incubated for $24 \mathrm{~h}$ at $37^{\circ} \mathrm{C}$ with $10 \mu \mathrm{M}$ bumetanide (BUM24H), after $24 \mathrm{H}$, the CK cocktail was added for additional $4 \mathrm{~h}$ (BUM24H + CKs4H). 
Immunofluorescence, imaging, and analysis

Organotypic cultures were fixed with $4 \%$ formaldehyde (prepared from fresh paraformaldehyde; Sigma) in PBS (1x) for $1 \mathrm{~h}$ at room temperature (RT; 20 to $22^{\circ} \mathrm{C}$ ) and washed in PBS. Free aldehyde groups were quenched in $0.1 \mathrm{M}$ glycine in PBS for $10 \mathrm{~min}$. Slices were permeabilized and blocked in PBS 1×, 5\% FBS (Sigma), 1\% BSA (Sigma), and $0.3 \%$ Triton X-100 (Sigma) at RT for $1 \mathrm{~h}$ and then incubated overnight at $4{ }^{\circ} \mathrm{C}$ with anti-GFAP (mouse monoclonal, 1:400, Sigma), anti-Iba1 (rabbit polyclonal, 1:200, Wako), anti-SMI32 (mouse monoclonal, 1:200, EMDMillipore), and anti-MAP 2 (mouse monoclonal, 1:200, Sigma) primary antibodies.

For $\beta$-tubulin III and GAD65/67 co-immuno-labeling, fixed samples were quenched with $\mathrm{Na}$-(meta) periodate $2.3 \%$ in deionized water for $5 \mathrm{~min}$ and $\mathrm{Na}$-borohydride $1 \%$ in TRIS $0.1 \mathrm{M}$ for $10 \mathrm{~min}$. Slices were blocked in freefloating with PBS $1 \times, 10 \%$ FBS (Sigma), 1\% BSA (Sigma), $1 \%$ fish gelatin (Sigma), and 0.3\% Triton X-100 (Sigma) at RT for $1 \mathrm{~h}$ and then incubated overnight at $4{ }^{\circ} \mathrm{C}$ with anti$\beta$-tubulin III primary antibody (mouse monoclonal; 1:500, Sigma) and anti-GAD65/67 (rabbit polyclonal; 1:500, ABCAM).

Subsequently, the slices were PBS-washed and incubated with secondary antibodies diluted in blocking solution for $2 \mathrm{~h}$ at RT in the dark. The secondary antibodies were Alexa 488 goat anti-mouse (1:500, Invitrogen), Alexa 488 goat anti-rabbit (1:500, Invitrogen), Alexa 594 goat anti-mouse (1:500, Invitrogen), Alexa 594 goat anti-rabbit (1:500, Invitrogen), and DAPI (Thermo Fisher Scientific). Samples were mounted on glass coverslips using Vectashield mounting medium (Vector Laboratories).

Images were acquired using Nikon $\mathrm{C} 2$ confocal microscopes with $\mathrm{Ar} / \mathrm{Kr}, \mathrm{He} / \mathrm{NE}$, and UV laser with $\times 20, \times 40$, or $\times 63$ oil objectives (1.4 N.A.) using oil mounting medium (1.515 refractive index). Confocal sections were acquired every $0.5 \mu \mathrm{m}$ up to a total $Z$-stack thickness of $5 \mu \mathrm{m}$. For each condition, we performed $>3$ and $<6$ independent cultures; from each culture series, we used 4 slices, and from each slice, $\geq 5$ fields were randomly acquired. Offline analysis of the image $Z$-stack was performed using the open source image-processing package FIJI (http://fiji.sc/Fiii).

For the quantitative analysis of microglia morphology, we used the particle measurement feature in ImageJ, to automatically measure the area and the perimeter, necessary to calculate the transformation index [25], as $\frac{[\text { perimeter of cell }(\mu \mathrm{m})]^{2}}{\left.4 \pi \cdot \operatorname{area} \text { of cell }\left(\mu \mathrm{m}^{2}\right)\right]}$, which defines microglia ramification status. Indeed, cells with long processes and small soma show a large index that depends on cell shape, regardless of the cell size.

Quantification of GAD65/67 immunoreactivity was performed measuring the intensity of fluorescence and the number of GAD65/67 clusters using the Volocity3D
Image Analysis Software. Clusters were determined after thresholding of images. Thresholds were determined using the "voxel spy" facility of the software and chosen such that all recognizable punctuate structures were included into the analysis (size $>0.03 \mu \mathrm{m}^{3}$ and separate touching objects of $0.5 \mu \mathrm{m}^{3}$ ).

\section{Electrophysiological recordings and data analysis}

For patch-clamp recordings (whole-cell, voltage clamp mode), a coverslip with the spinal culture was positioned in a recording chamber, mounted on an inverted microscope (Nikon Eclipse TE200) and superfused with a standard saline solution containing $(\mathrm{mM}) 152 \mathrm{NaCl}, 4$ $\mathrm{KCl}, 1 \mathrm{MgCl} 2,2 \mathrm{CaCl} 2,10 \mathrm{HEPES}$, and 10 glucose; the $\mathrm{pH}$ was adjusted to 7.4 by $\mathrm{NaOH}$ (305 mOsm). Patch pipettes were pulled from borosilicate glass capillaries (4 to $7 \mathrm{M} \Omega$ ) and filled with intracellular solution containing $(\mathrm{mM}) 120 \mathrm{~K}$ gluconate, $20 \mathrm{KCl}, 10 \mathrm{HEPES}, 10 \mathrm{EGTA}, 2$ $\mathrm{MgCl}_{2}$, and $2 \mathrm{Na}_{2} \mathrm{ATP}$. The $\mathrm{pH}$ was adjusted to 7.3 with $\mathrm{KOH}$ (295 mOsm). All electrophysiological recordings were performed at RT. The reported voltage values are corrected for the liquid junction potential $(-14 \mathrm{mV})$ [26]. Electrophysiological responses were amplified (EPC-7, HEKA), sampled, and digitized at $10 \mathrm{kHz}$ with the pCLAMP software (Axon Instruments) for offline analysis. The value of series resistance was $<10 \mathrm{M} \Omega$ enabling recordings of synaptic currents without significant distortion and thus was not compensated for $[16,26]$. Recordings were performed from ventrally located spinal interneurons visually identified based on previously reported criteria [27]. Spontaneous post-synaptic currents (PSCs) were recorded at $-70 \mathrm{mV}$ holding potential by the Clampfit 10 software (pClamp suite, Axon Instruments). On average, $\geq 400$ events were analyzed from each cell in order to obtain mean kinetic and amplitude parameters. From the average of these events, we measured the rise time defined as the 10-90\% time needed to reach the peak of the synaptic current, the peak amplitude, and the decay time constant $(\tau)$ that was obtained by fitting a mono-exponential function [27].

We compared the passive membrane properties among control and CK- and LPS-treated spinal interneurons. We detected no differences in cell capacitance $(51 \pm 31 \mathrm{pF}$ control; $43 \pm 23 \mathrm{pF}$ CKs $4 \mathrm{H} ; 43 \pm 21 \mathrm{pF}$ CKs $6 \mathrm{H} ; n=62$, 47,54 respectively; $55 \pm 23 \mathrm{pF}$ control; $44 \pm 18 \mathrm{pF}$ LPS $4 \mathrm{H}$; $48 \pm 22 \mathrm{pF}$ LPS $6 \mathrm{H} ; n=35,38,34$, respectively) and input resistance $(470 \pm 195 \mathrm{M} \Omega$ control; $587 \pm 137 \mathrm{M} \Omega \mathrm{CKs} 4 \mathrm{H}$; $481 \pm 114 \mathrm{M} \Omega$ CKs $6 \mathrm{H} ; 430 \pm 123 \mathrm{M} \Omega$ control; $399 \pm 121$ $\mathrm{M} \Omega$ LPS $4 \mathrm{H} ; 439 \pm 146 \mathrm{M} \Omega$ LPS $6 \mathrm{H})$.

Inhibitory GABAergic post-synaptic currents (IPSCs) were recorded at $-84 \mathrm{mV}$ holding potential in the presence of CNQX (10 $\mu \mathrm{M}$; Sigma), strychnine (1 $\mu \mathrm{M}$; Sigma), and APV $(25 \mu \mathrm{M}$; Sigma). Tetrodotoxin (TTX; $1 \mu \mathrm{M}$, 
Latoxan) was used to isolate $\mathrm{GABA}_{\mathrm{A}}$-receptor-mediated miniature events (mIPSCs).

Recordings of the IPSCs at different holding potentials were used to measure the chloride equilibrium potential $\left(E_{\mathrm{Cl}}\right)$, which was determined as the $x$-axis intercept point of the resulting I/V curve extrapolated by linear regression.

The imidazopyridine zolpidem (zolpidem, Sigma), a benzodiazepine ligand with high selectivity for $\mathrm{GABA}_{\mathrm{A}} \mathrm{Rs}$ containing the $\alpha 1$-subunit and moderate affinity to $\alpha 2$ - or $\alpha 3$-subunit, [28], was dissolved in water stock solution (1 $\mathrm{mM}$ ) and diluted to the concentration of $100 \mathrm{nM}$ [29] in extracellular solution for bath application (15-20 min).

\section{Cytokine and chemokine measurement}

TNF- $\alpha$, IL-4, IL-6, IL-10, INF- $\gamma$, CXCL1, and CXCL2 concentrations were measured in organotypic culture supernatants by Milliplex assay (Merck Millipore, \#MCYTOMAG$70 \mathrm{k}$ ), using the Bio-Plex apparatus (Biorad), according to the manufacturer's recommendations.

\section{Statistical analysis}

All values from samples subjected to the same experimental protocols were pooled together, and results are presented as mean \pm S.D., if not stated otherwise, with $n=$ number of neurons. A statistically significant difference between two data sets was assessed by Student's $t$ test (after checking variances homogeneity by Levene's test) for parametric data and by Mann-Whitney's test for nonparametric ones. Two-way analysis of variance (two-way ANOVA) and one-way ANOVA were used for parametric data or Kruskal-Wallis test for non-parametric ones, to determine significance when multiple groups were compared. Statistical significance was determined at $P<0.05$.

In box plots, the thick horizontal bar indicates the median value, the cross indicates the mean value, the boxed area extends from the 25 th to 75 th percentiles while whiskers from the 5th to the 95th percentiles.

\section{Results}

CKs but not LPS regulate $\mathrm{GABA}_{\mathrm{A}}$ receptor-mediated synaptic currents in spinal organotypic cultures

We used organotypic spinal cord and DRG co-cultures (Fig. 1a) to study the impact of neuroinflammation on the GABAergic synaptic transmission within ventral horn premotor circuits [16]. Two different danger signals were used to trigger neuroinflammation in cultured slices: a proinflammatory cocktail of CKs [17] and LPS [19]. In both conditions, after $4 \mathrm{H}$ and $6 \mathrm{H}$ treatments (see the "Methods" section), patched clamped ventral interneurons displayed a significant increase in the frequency of spontaneous PSCs (represented by heterogeneous inward currents of variable amplitudes, see Additional file 2: Figure S1 A-D) in accordance with previous reports $[5,17,30,31]$.
Since fast $\mathrm{Cl}^{-}$-mediated neurotransmission is a potential pro-inflammatory cytokine target in spinal circuits $[5,17,32]$, we recorded $\mathrm{GABA}_{\mathrm{A}}$ receptor-mediated synaptic events (IPSCs; Fig. 1b) pharmacologically isolated in the presence of CNQX $(10 \mu \mathrm{M})$, APV $(25 \mu \mathrm{M})$, and strychnine $(1 \mu \mathrm{M})$, to block AMPA, NMDA, and glycine receptor-mediated synaptic currents [17]. CK and LPS treatments increased IPSC frequency, without altering IPSC amplitudes (sample tracings in Fig. 1b and box plots in Additional file 3: Figure S2 A and B), when compared to control.

We next explored the kinetic properties of the IPSCs. Consistent with our preliminary findings [17], CK treatments $(4 \mathrm{H}$ and $6 \mathrm{H}, n=33$ and 37 , respectively) significantly accelerated the IPSC decay time constant $(\tau)$ $(23.7 \pm 6.5 \mathrm{~ms}$ CKs $4 \mathrm{H} ; 25.7 \pm 6.6 \mathrm{~ms}$ CKs $6 \mathrm{H}$; Fig. 1c, top, box plot and scaled averaged IPSCs are superimposed in the inset) when compared to control (31.5 \pm $9.6 \mathrm{~ms}$ control, $n=40$; ${ }^{* * * *} P<0.001$ control vs CKs $4 \mathrm{H}$, $* P=0.004$ control vs CKs $6 \mathrm{H}$; Fig. 1c). Conversely, LPS (4H and $6 \mathrm{H}, n=34$ and 28 , respectively) left the $\tau$ of the IPSCs unchanged $(27.9 \pm 7.1 \mathrm{~ms}$ LPS $4 \mathrm{H} ; 28.1 \pm 6.3 \mathrm{~ms}$ LPS $6 \mathrm{H})$ in respect to control $(29.1 \pm 7.4 \mathrm{~ms}$ control, $n=$ 37; Fig. 1c, bottom box plot and scaled averaged IPSCs are superimposed in the inset). The IPSC rise-time values (Additional file 3: Figure S2 C) were unaffected by all treatments. Since IPSC decay time may be developmentally regulated [32], we plotted the $\tau$ values detected in control and in $\mathrm{CKs} 4 \mathrm{H}$ and $6 \mathrm{H}$ against two time of growth in vitro. Bar plots in Fig. 1d show that CKs shortened the GABAergic current duration at any age of maturation in vitro, thus excluding a correlation between the CK modulation of IPSC decay time and the developmental stage of spinal cord slices in vitro.

We extended our characterization to the properties of miniature GABAergic currents (mPSCs; recorded in the presence of TTX). The results in this group of cells (Fig. 1e) confirmed that CKs affected mPSC decay kinetics (mPSCs $\tau$ value $40.9 \pm 11.7 \mathrm{~ms}$ in control; 29.4 \pm 11.6 $\mathrm{ms}$ in CKs $4 \mathrm{H} ; 24.3 \pm 6.4 \mathrm{~ms}$ in CKs $6 \mathrm{H} ; n=9,7$, 9, respectively; ${ }^{*} P=0.024$ control vs $\mathrm{CKs} 6 \mathrm{H}$ ) with a trend similar to that of spontaneous IPSCs. mIPSC decay time remained unchanged upon LPS treatments $(30.2 \pm 5.9$ ms control; $29.3 \pm 4.3 \mathrm{~ms}$ LPS $4 \mathrm{H} ; 30.2 \pm 5.3 \mathrm{~ms}$ LPS $6 \mathrm{H}$; $n=5,5,5$, respectively; Fig. 1e, bottom) in accordance with the spontaneous IPSCs.

We next examined by immunofluorescence the presence and distribution of GABAergic neurons in spinal ventral horns, targeting either isoforms of GABAsynthesizing enzyme (glutamate decarboxylase, GAD), namely GAD65/67 [33]. We quantified and compared GAD65/67 labeling in all conditions (Additional file 4: Figure S3, A-D). Immunoreactivity for GAD65/67 was visible throughout the spinal explants where neurons 


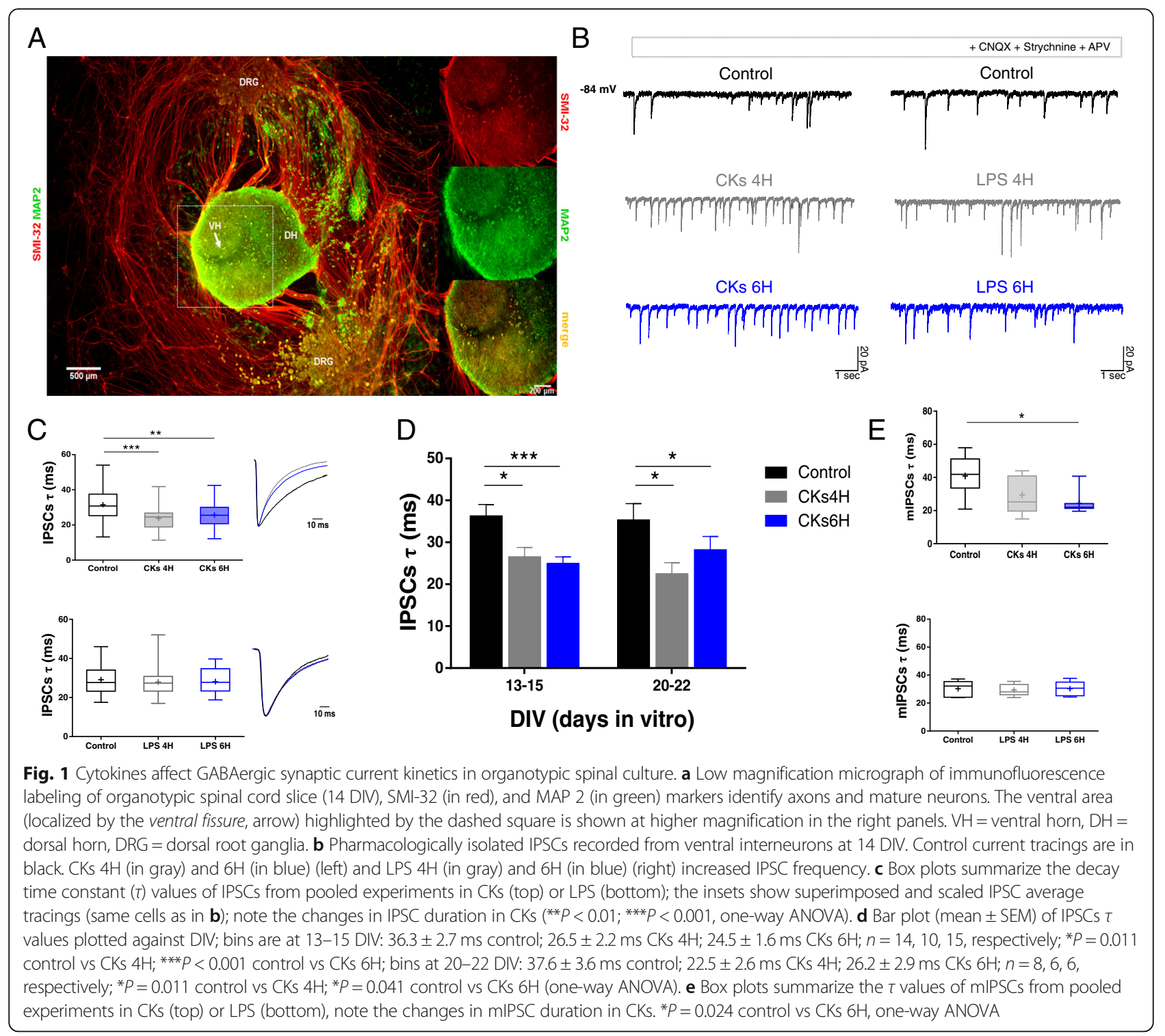

were visualized using a specific marker (class III $\beta$ tubulin, Additional file 4: Figure S3 A and C). At lower magnification, scattered soma, extensive neural processes, and bouton-like structures (named clusters, see the "Methods" section) appeared to be stained for both GAD isoforms and were not affected by CK or LPS treatments, quantified in Additional file 4: Figure S3 B and D.

\section{Resident neuroglia reactivity to CKs and LPS in spinal organotypic slices}

In response to different microenvironment stimuli, microglia and astrocytes may switch to active states, highlighted by changes in cell function, number, and/or morphology. Microglia and astrocytes were visualized in organotypic spinal explants by Iba1 and GFAP co-immunolabeling, shown in Fig. $2 \mathrm{a}$ and $\mathrm{b}$.

CKs $4 \mathrm{H}$ and $6 \mathrm{H}$ promoted a significant increase in Ibal $^{+}$cells $\left(99.8 \pm 5.5\right.$ cells $/ \mathrm{mm}^{2}$ control; $155.3 \pm 21.5$ cells $/ \mathrm{mm}^{2}$ CKs $4 \mathrm{H} ; 183.7 \pm 15.7$ cells $/ \mathrm{mm}^{2}$ CKs $6 \mathrm{H}$; $* P=0.032$ control vs $\mathrm{CKs} 4 \mathrm{H} ;{ }^{* * * *} P<0.001$ control vs CKs $6 \mathrm{H}$; summarized in Additional file 1: Table S1 for $4 \mathrm{H}$ and in Fig. 2c, left, for $6 \mathrm{H}$ ). The same treatments promptly induced a significant increase in GFAP intensity $(158.1 \pm 35.7 \%$ CKs $4 \mathrm{H} ; 229.3 \pm 37.3 \%$ CKs $6 \mathrm{H} ;{ }^{*} P=0.024$ control vs $\mathrm{CKs} 4 \mathrm{H}$, ${ }^{* * *} P<0.001$ vs CKs $6 \mathrm{H}$; ${ }^{* * *} P<0.001 \mathrm{CKs} 4 \mathrm{H}$ vs $\mathrm{CKs} 6 \mathrm{H}$; summarized in Additional file 1: Table $\mathrm{S} 1$ for $4 \mathrm{H}$ and Fig. 2c, right, for $6 \mathrm{H}$ ). Differently, LPS, summarized for $4 \mathrm{H}$ in Additional file 1: Table S1 and in the plots in Fig. 2d 


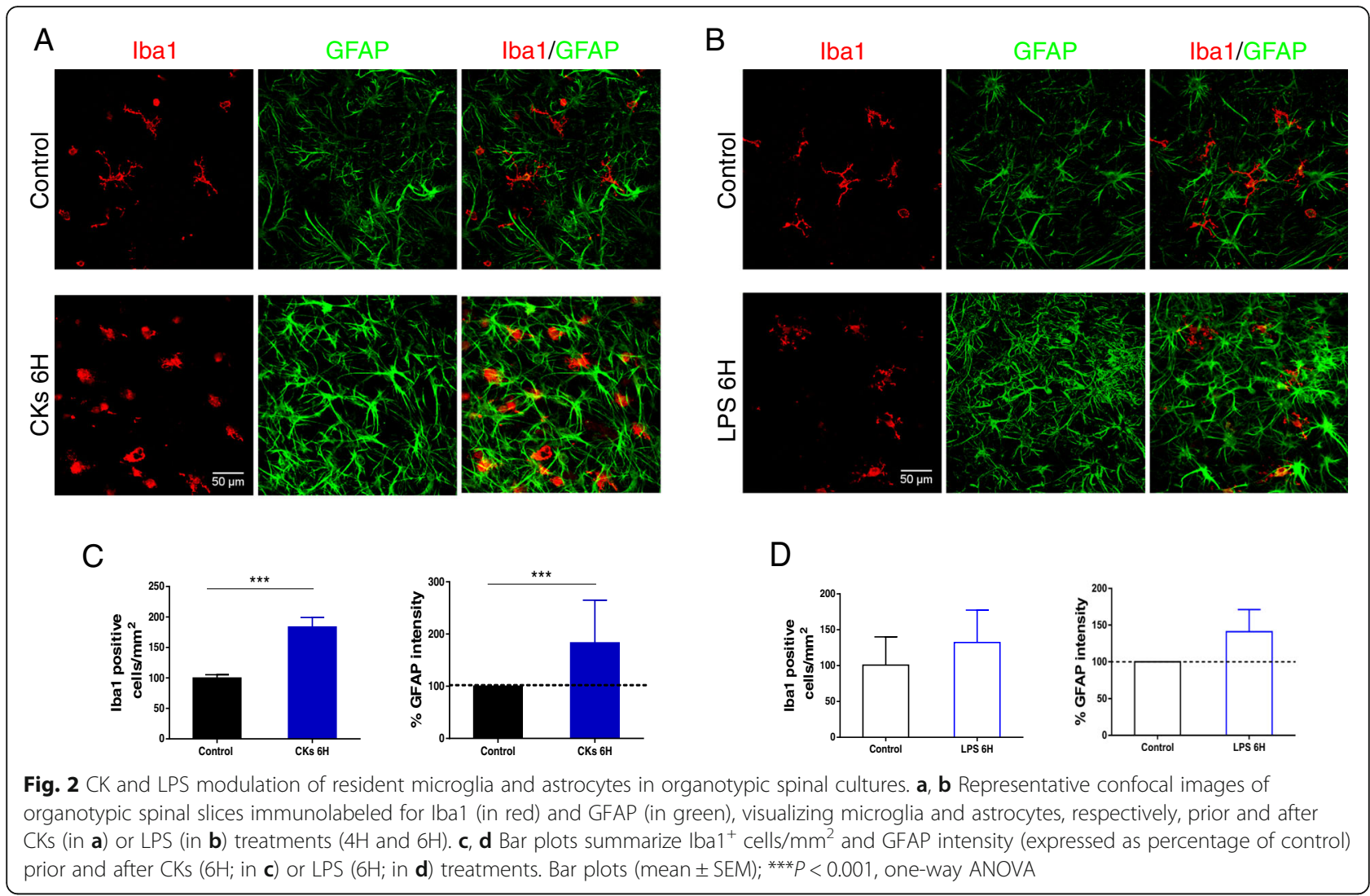

for $6 \mathrm{H}$, provoked only mild increases in $\mathrm{Iba}^{+}$cells $\left(100.8 \pm 8.2 \mathrm{cell} / \mathrm{mm}^{2}\right.$ control; $112.8 \pm 7.4 \mathrm{cell} / \mathrm{mm}^{2}$ LPS $4 \mathrm{H} ; 132.2 \pm 11.7 \mathrm{cell} / \mathrm{mm}^{2}$ LPS $\left.6 \mathrm{H}\right)$ and in the GFAP intensity $(110.4 \pm 18.7 \%$ LPS $4 \mathrm{H} ; 141.1 \pm 15.1 \%$ LPS $6 \mathrm{H})$.

We further assessed CK and LPS ability to shape the morphology of $\mathrm{Iba}^{+}$microglia at $6 \mathrm{H}$. To this aim, we quantified the total dendrite length [34] together with the transformation index (results summarized in Fig. 3a, b; [25]). Upon CKs $6 \mathrm{H}$ treatments, microglia showed a significant decrease in both the total dendrite lengths $\left(270.3 \pm 144.8 \mu \mathrm{m}\right.$ control; $93.8 \pm 81.2 \mu \mathrm{m} \mathrm{CKs} 6 \mathrm{H}$; ${ }^{* * *} \mathrm{P}<$ 0.001 control vs $\mathrm{CKs} 6 \mathrm{H}$ ) and the transformation index $\left(2.7 \pm 2.4\right.$ control; $1.7 \pm 0.7 \mathrm{CKs} 6 \mathrm{H} ;{ }^{*} \mathrm{P}<0.005$ control vs CKs $6 \mathrm{H})$. In parallel, in slices stimulated by LPS, we observed, at $6 \mathrm{H}$, changes in microglia morphology that seem to indicate a different stage of activation [35]. In fact, Fig. 3 $\mathrm{a}$ and $\mathrm{b}$ show a significant increment of the Iba $1^{+}$cell dendrite length at LPS $6 \mathrm{H}(346.6 \pm 194.9 \mu \mathrm{m}$ control; $472.6 \pm$ $255.9 \mu \mathrm{m}$ LPS $6 \mathrm{H} ;{ }^{* * *} P<0.001$ control vs LPS $\left.6 \mathrm{H}\right)$ and of the transformation index (7.2 \pm 5.3 control; $12.2 \pm 7.7$ LPS $6 \mathrm{H}$; ${ }^{* * *} P<0.001$ control vs LPS $\left.6 \mathrm{H}\right)$. Finally, we evaluated and compared the production of cytokines and chemokines by spinal slices in response to pro-inflammatory stress at $6 \mathrm{H}$ (for CKs $n=14$ slices and for LPS $n=22$ slices, from 3 different culture series). The summarizing plots of Fig. 3c, d show that the exposure to CKs (c) and LPS (d) significantly increased, although to a different extent, the release of pro-inflammatory cytokines, measured in the supernatant, such as TNF- $\alpha$, IL-6, and INF- $\gamma$, as well as the release of chemokines including CXCL1 and CXCL2 necessary for the recruitment of innate immune cells. Interestingly, IL-4 and IL-10 are significantly raised upon CK stimuli, but are not changed after LPS treatments. The different pro- and anti-inflammatory cytokine network, in addition to the production of chemokines, suggests the induction of alternative activation mechanisms in spinal slices stimulated by CKs and LPS at the time point $(6 \mathrm{H})$ analyzed.

In the central nervous system, LPS binds to the Tolllike receptors (TLRs), especially TLR4, expressed on the microglia surface. This signal involves several proteins resulting in the production and release of cytokines, chemokines, and other inflammatory factors [36]. Since LPS, differently from CKs [37], may not act directly on neurons, we tested whether a longer $(24 \mathrm{H})$ exposure to LPS may ultimately lead to changes in GABAergic transmission and kinetic. Figure 4 reports the effects of LPS $24 \mathrm{H}$ in terms of PSC frequency $(21.7 \pm 6.7 \mathrm{~Hz}$ control; $30.5 \pm 5.0 \mathrm{~Hz}$ LPS $24 \mathrm{H} ; n=8$ and 12 , respectively; ${ }^{* *} P=$ 0.003 control vs LPS $24 \mathrm{H}$; Fig. 4a), IPSC frequency $\left(1.2 \pm 0.8 \mathrm{~Hz}\right.$ control; $2.5 \pm 0.9 \mathrm{~Hz}$ LPS $24 \mathrm{H} ;{ }^{* *} P=0.007$ 


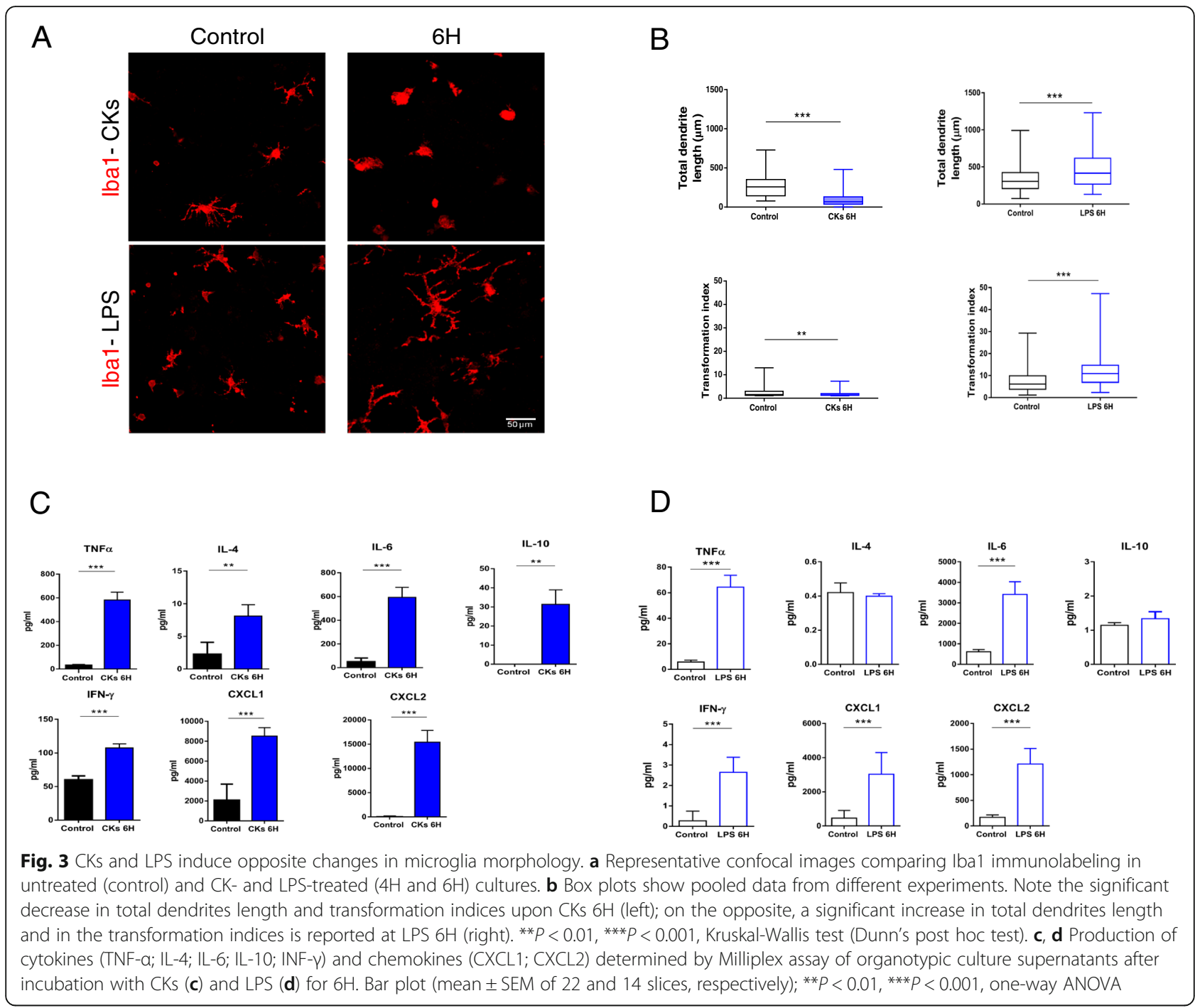

control vs LPS 24H; Fig. 4b), and IPSC decay time constant $(32.7 \pm 10.2 \mathrm{~ms}$ control; $29.7 \pm 5.5 \mathrm{~ms}$ LPS $24 \mathrm{H}$, Fig. 4c, scaled averaged IPSCs are superimposed in the inset). In addition, Iba1 ${ }^{+}$cells at LPS $24 \mathrm{H}$ (Fig. 4 D) displayed the characteristic morphology with longer branching in ramified cells (quantified in plots of Fig. 4d, total dendrites length: $249.6 \pm 96.0 \mu \mathrm{m}$ control; $393.4 \pm$ $216.9 \mu \mathrm{m}$ LPS $24 \mathrm{H}$; ${ }^{* * *} P<0.001$ control vs LPS $24 \mathrm{H}$; transformation indices: $5.2 \pm 3.1$ control; $8.6 \pm 7.1$ LPS $24 \mathrm{H})$. These results indicated that the kinetic of GABAergic currents was not modulated by longer incubation in this danger signal, and the effects on microglia dendrite lengths stabilized after $6 \mathrm{H}$.

\section{CKs modulate GABAergic current duration through changes in $\mathrm{GABA}_{A} \mathrm{R}$ subunits composition}

We further explored the mechanisms responsible for IPSC shortening due to CKs. The decay of IPSCs is also faster, upon CK treatments, in unitary synaptic events
(mIPSCs), ruling out the involvement of presynaptic processes affecting IPSC time course, such as neurotransmitter release synchronization. Moreover, the absence of changes in IPSC rise time (Additional file 3: Figure S2 C) suggests that differences in recording conditions, location of synapses or electronic filtering, are unlikely to have affected our observations.

Differences in the intracellular chloride concentration $\left[\mathrm{Cl}^{-}\right]_{\mathrm{i}}$ were reported to affect IPSC kinetics $[38,39]$. We incubated organotypic slices with bumetanide $(10 \mu \mathrm{M}$; $24 \mathrm{H}, \quad n=11)$, a blocker of NKCC1 activity [24], a membrane-protein described as the most abundant cotransporter determining intracellular chloride levels [40], to experimentally reduce $\left[\mathrm{Cl}^{-}\right]_{\mathrm{i}}$ prior to CKs $4 \mathrm{H}(n=10$; see sketch of the experimental settings in Fig. 5a).

Bumetanide per se induced an increase in PSC and IPSC frequencies that were slightly, although not significantly, further improved by CKs $4 \mathrm{H}$ (Fig. 5b for sample tracings and Additional file 5: Figure S4). More intriguingly, bumetanide 


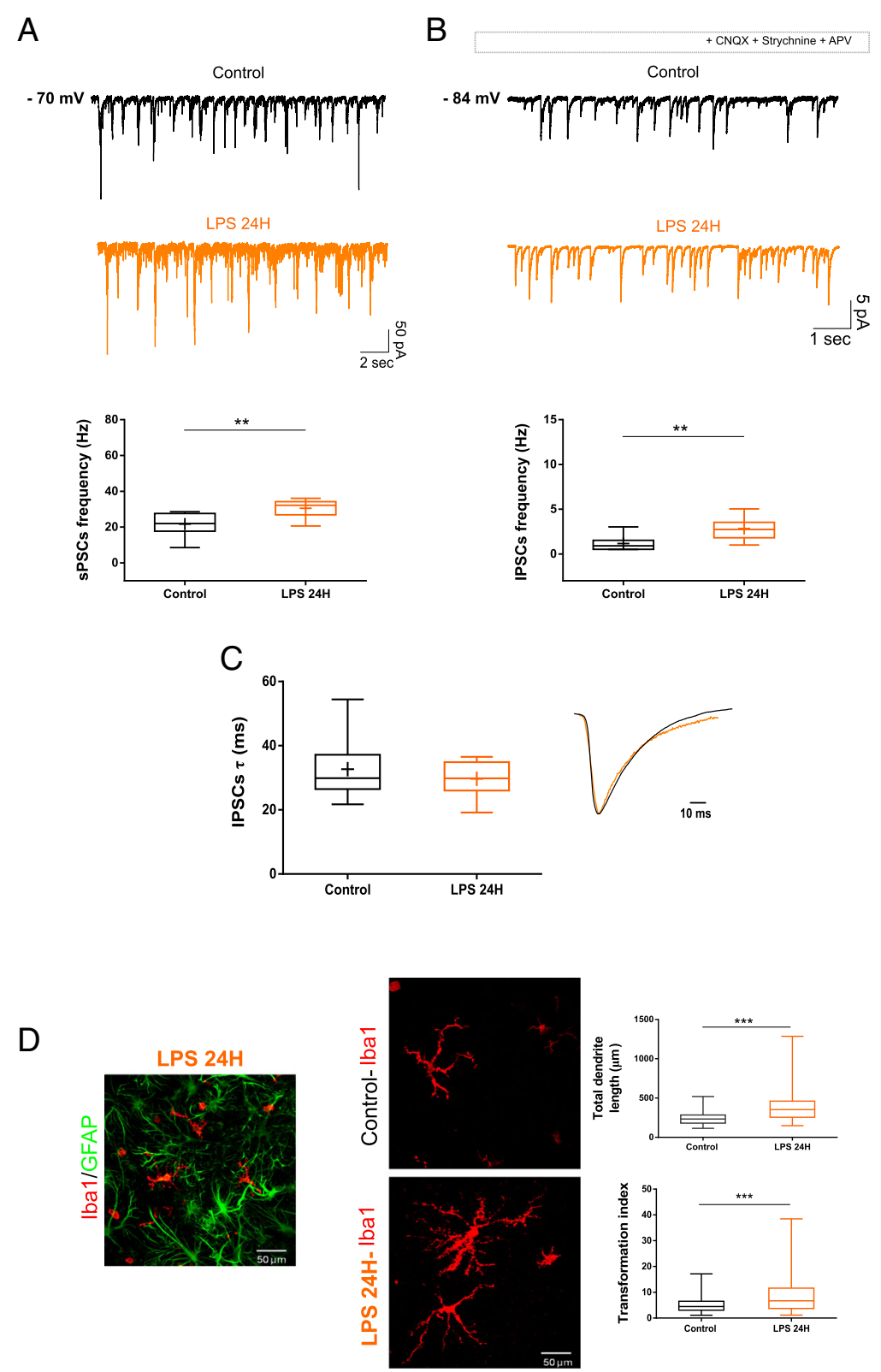

Fig. 4 Long-term exposure to LPS in organotypic spinal slices is not altering GABAergic currents. a Representative traces of spontaneous PSCs recorded from control (in black) and LPS 24H (in orange) ventral interneurons. The box plot shows a significant increase in PSC frequency upon LPS 24H. ${ }^{* *} P=0.003$, Mann-Whitney test. b Pharmacologically isolated IPSCs are recorded from control (in black) and LPS $24 \mathrm{H}$ (in orange) ventral interneuron (same cells as in a). The box plot summarizes the IPSC frequency from pooled experiments and exhibits a significantly increased frequency brought about by LPS $24 \mathrm{H}$. ${ }^{*} P=0.007$, Mann-Whitney test. $\mathbf{c}$ The box plot summarizes the values of $\tau$ for control and LPS; in the inset, averaged scaled and superimposed traces of the two conditions are shown. Note that no changes were detected in IPSC decay time constant. d Left, representative image of the LPS 24H-treated organotypic culture labeled with GFAP (green) and Iba1 (red). Right, high magnification Iba1 micrographs are shown (middle), and plots summarize the morphology changes of microglia upon LPS 24H. Note the significant increase in dendrites length (top) and in the transformation index (bottom); ${ }^{* *} P<0.001$, Mann-Whitney test

reduced significantly the duration of GABAergic currents ( $\tau=33.1 \pm 8.1 \mathrm{~ms}$ control; $\tau=22.3 \pm 6.2 \mathrm{~ms}$ BUM $24 \mathrm{H}$; ** $P=0.005$ control vs BUM $24 \mathrm{H}$ ) that were not further shortened by CKs $4 \mathrm{H}(\tau=22.3 \pm 6.5 \mathrm{~ms}$ BUM $24 \mathrm{H}+\mathrm{CKs}$ $4 \mathrm{H} ;{ }^{*} \mathrm{P}=0.012$ control vs BUM $24 \mathrm{H}+\mathrm{CKs} 4 \mathrm{H}$; Fig. 5c).
Figure $5 \mathrm{~d}$ shows the measurement of the reversal potential of IPSCs in control, BUM $24 \mathrm{H}$, and BUM $24 \mathrm{H}+$ CKs $4 \mathrm{H}$. The estimated $E_{\mathrm{Cl}}$ value in control $(-48.5 \pm 3.7 \mathrm{mV}$; $n=7$ ) was close to the approximate theoretical value expected for the $\mathrm{Cl}^{-}$equilibrium potential for our 
A
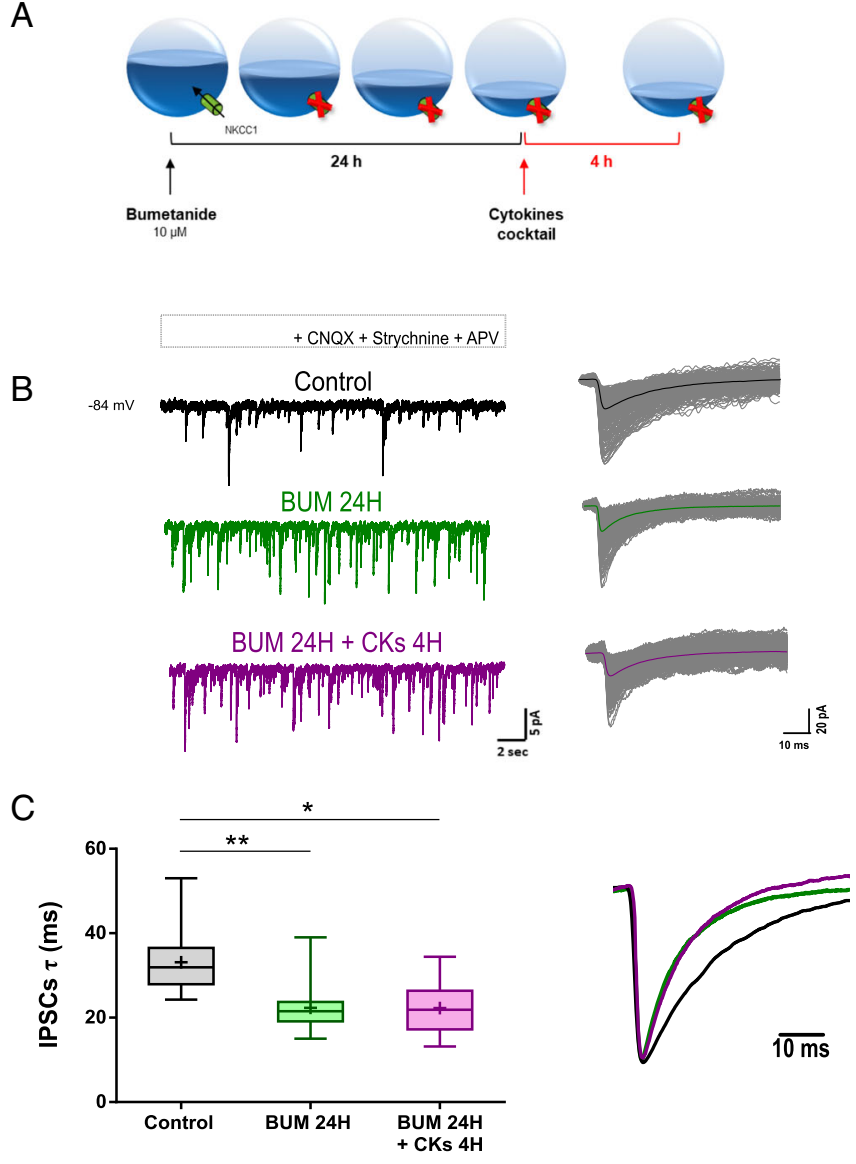

D
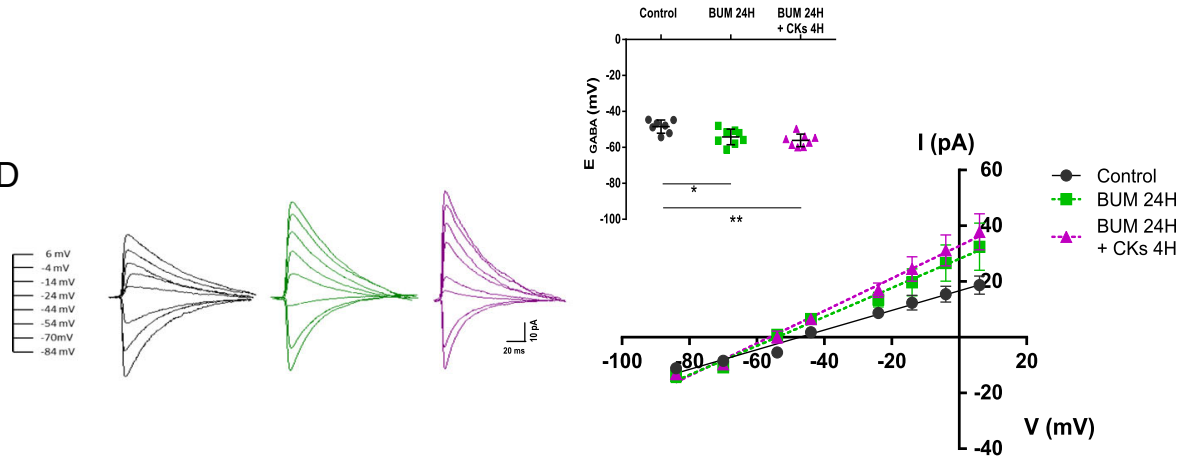

Fig. 5 Effects of CKs on GABAergic synaptic current duration in the presence of bumetanide. a Sketch of the protocol used to treat slices with bumetanide for 24H (BUM 24H) followed by CKs 4H. b Representative traces (left) and superimposed isolated events (right) of IPSCs in control, after BUM 24H (green), and BUM 24H + CKs 4H (magenta). c The box plot summarizes the IPSCS $T$ values measured in the three conditions; note the significant reduction in IPSCS $\tau$ in BUM $24 \mathrm{H}$ and BUM $24 \mathrm{H}+\mathrm{CKs} 4 \mathrm{H}$, in respect to control. Inset: superimposed averaged and scaled IPSCs in the three conditions. ${ }^{*} P=0.012,{ }^{* *} P=0.005$, Kruskal-Wallis test. $\mathbf{d}$ Top, IPSCS averaged and superimposed traces recorded at different $\mathrm{V}_{\mathrm{h}}$ in control (black), BUM $24 \mathrm{H}$ (green), and BUM 24H + CKs 4H (magenta). Bottom, IN curves obtained by plotting GABA $A_{A}$ IPSCs mean amplitude against $V_{h}$. Note in the inset the significant differences in the estimated IPSCs reversal potential $\left(E_{G A B A}\right)$ at BUM $24 \mathrm{H}$ and BUM $24 \mathrm{H}+C \mathrm{CKs} 4 \mathrm{H}$, when compared to control. ${ }^{*} P<0.05$, ${ }^{* *} P<0.01$, one-way ANOVA

intracellular and extracellular chloride concentrations (- 50 $\mathrm{mV}$; [26]). However, the reversal potential was significantly shifted to more negative values by blocking NKCC1 $\left(-54.2 \pm 4.3 \mathrm{mV}\right.$ BUM $24 \mathrm{H}, n=8 ;{ }^{*} P=0.025$ control vs BUM $24 \mathrm{H}$ ), suggesting that local intracellular chloride concentrations are lower (estimated from 24 to $19 \mathrm{mM}$ ). It is important to note that in organotypic cultures, upon bumetanide treatments, the $\mathrm{Cl}^{-}$reversal potential differed from the predicted theoretical value, suggesting a real shift in the internal chloride concentration as a result of reduced 
co-transport $[41,42]$, regardless the $24 \mathrm{mM} \mathrm{Cl}^{-}$intracellular pipette solution [17].

Pro-inflammatory CKs, in the presence of NKCC1 block, slightly increased such a shift only when compared to controls $(-56.2 \pm 3.5 \mathrm{mV}$ BUM $24 \mathrm{H}+\mathrm{CKs} 4 \mathrm{H} ; n=8$; $* P=0.003$ control vs BUM $24 \mathrm{H}+\mathrm{CKs} 4 \mathrm{H})$. The absence of significant changes in IPSC decay time constant and reversal once CKs were incubated in the presence of bumetanide might indicate an occluding mechanisms between CKs and bumetanide in regulating $\left[\mathrm{Cl}^{-}\right]_{\mathrm{i}}$.

To shed light in CK potential regulation of intracellular chloride, and thus of IPSCs $\tau$, we estimated and compared $E_{\mathrm{Cl}}$ in control, CKs, and LPS treatments. Additional file 6: Figure S5 shows that the reversal potential of IPSCs was not altered by these treatments alone $(-52.0 \pm 7.5 \mathrm{mV}$ control; $-51.5 \pm 5.2 \mathrm{mV} \mathrm{CKs} 4 \mathrm{H} ; n=9,10$, respectively; $49.6 \pm 7.8 \mathrm{mV}$ control; $-49.7 \pm 9.9 \mathrm{mV}$ LPS $4 \mathrm{H} ; n=13,8$, respectively). Regardless of the similar $E_{\mathrm{Cl}}$ extrapolated in all the recording conditions, only $\mathrm{CKs} 4 \mathrm{H}$ induced the expected changes in the IPSC duration $(\tau=31.8 \pm 5.1 \mathrm{~ms}$ control; $\tau=23.9 \pm 8.1 \mathrm{~ms} \mathrm{CKs} 4 \mathrm{H} ;{ }^{*} P=0.031$ control vs CKs 4H; Student $t$ test; $\tau=26.4 \pm 5.2 \mathrm{~ms}$ control; $\tau=$ $26.2 \pm 6.3 \mathrm{~ms}$ LPS $4 \mathrm{H}$; respectively). These results show that changes in $E_{\mathrm{Cl}}$ might indeed modulate IPSC duration in the organotypic spinal interneurons; however, CKs apparently are not tuning the inhibitory current duration by shifts in the $E_{\mathrm{Cl}}$.

A well-documented post-synaptic process that changes GABAergic inhibition is the switch in the $\alpha 1$-subunit expression reported to modulate IPSC kinetics, which become faster [43]. To address the potential changes in the receptor subunit composition due to $\mathrm{CK}$ treatment, we tested IPSC kinetics in the presence of zolpidem (100 $\mathrm{nM} ; 15-20 \mathrm{~min})$, an allosteric modulator of $\mathrm{GABA}_{\mathrm{A}} \mathrm{R}$ subunits that at low concentrations is highly selective for the $\mathrm{GABA}_{\mathrm{A}} \mathrm{R} \alpha 1$ subunit [44]. Figure $6 \mathrm{a}$ shows sample superimposed isolated IPSCs recorded from control, CKs $4 \mathrm{H}$, and CKs $6 \mathrm{H}$, before and after zolpidem applications. Also, in this set of recordings, after CKs $4 \mathrm{H}$ and $6 \mathrm{H}$, IPSCs $\tau$ was significantly reduced $(33.3 \pm 4.5 \mathrm{~ms}$ control; $25.4 \pm 4.7 \mathrm{~ms}$ CKs $4 \mathrm{H} ; 26.0 \pm 4.0 \mathrm{~ms}$ CKs $6 \mathrm{H} ; n=9$, 10, 9, respectively; ${ }^{*} P=0.019$ control vs $C K s 4 \mathrm{H} ;{ }^{*} P=$ 0.045 control vs $\mathrm{CKs} 6 \mathrm{H})$. Subsequent applications of zolpidem did not alter IPSCs $\tau$ in control $(36.3 \pm 3.9 \mathrm{~ms})$, while significantly prolonged $\tau$ values detected in CKs $4 \mathrm{H}$ and $6 \mathrm{H}(34.5 \pm 6.9 \mathrm{~ms} \mathrm{CKs} 4 \mathrm{H} ; 34.2 \pm 6.0 \mathrm{~ms} \mathrm{CKs}$
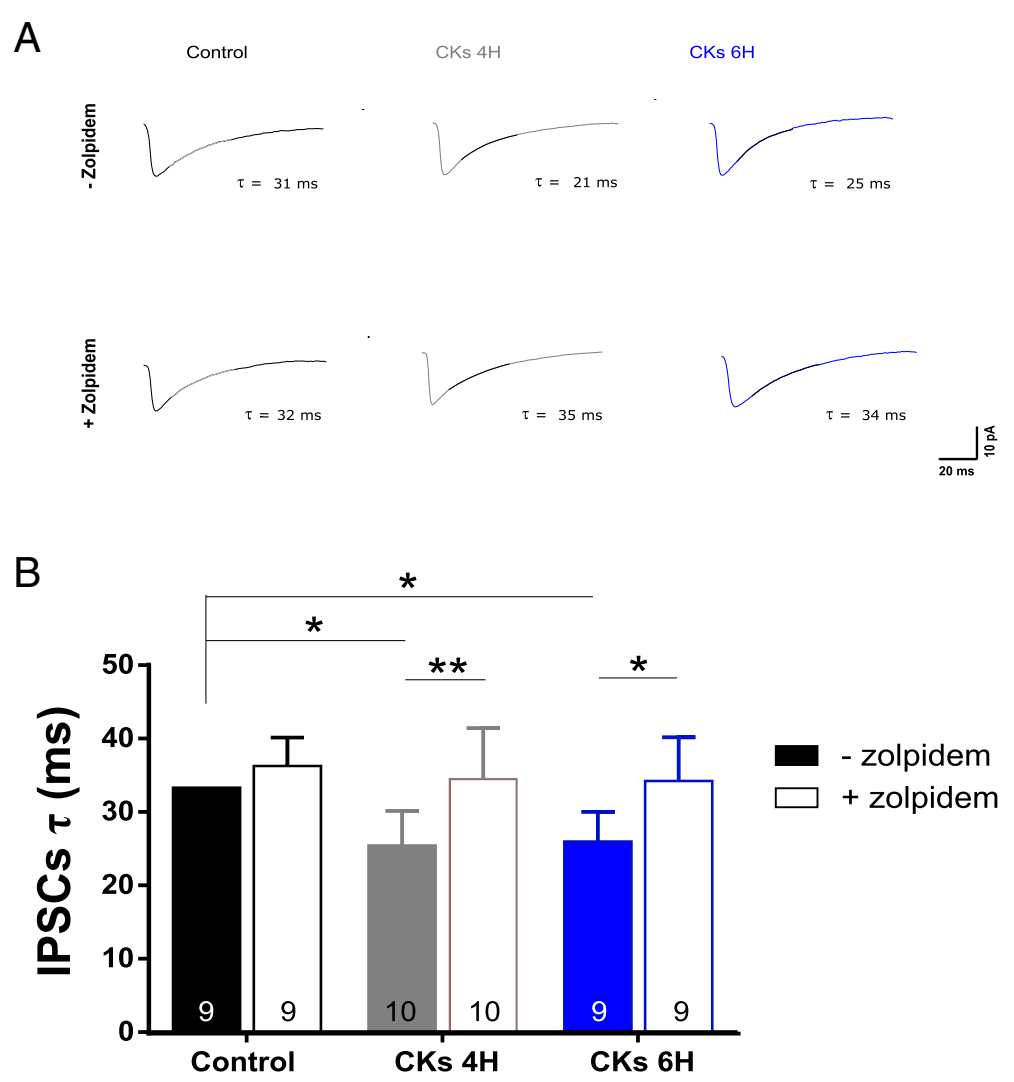

Fig. 6 Zolpidem effects on GABAergic synaptic current duration before and after CK treatments. a Sample tracings of averaged IPSCs recorded in control (black) and $\mathrm{CKs}$ (4H in gray and $6 \mathrm{H}$ in blue) in the presence $(+)$ or in the absence $(-)$ of zolpidem. Note the superimposed fitting used to calculate $\tau$ values. b Bar plot summarizes the $\tau$ values of IPSCs in control, $\mathrm{CKs} 4 \mathrm{H}$, and CKs $6 \mathrm{H}$, before and after bath application of zolpidem. Note that the significant decrease in IPSCS $\mathrm{T}$ upon CKs treatments $(4 \mathrm{H}$ and $6 \mathrm{H})$ was reversed by zolpidem. ${ }^{*} P<0.05,{ }^{*} P<0.01$, one-way ANOVA 
$6 \mathrm{H}$; ${ }^{* *} P=0.003 \mathrm{CKs} 4 \mathrm{H}-$ Zolpidem vs CKs $4 \mathrm{H}+$ zolpidem; $" P=0.017$ CKs $6 \mathrm{H}$-zolpidem vs CKs $6 \mathrm{H}+$ zolpidem), which did not differ anymore from control IPSCs (summarized in the bar plots of Fig. 6 B). These results strongly suggest that $\mathrm{CK}$ treatments regulated the duration of GABAergic inhibition via post-synaptic changes of the $\alpha 1$ subunit.

\section{Discussion}

Our study targets synaptic changes in response to local CNS tissue reactivity, experimentally induced by CKs or LPS and involving resident neuroglia. In particular, we used the spinal organotypic cultures to focus on the interplay between local inflammation and the dynamics of GABAergic currents, whose altered decay may represent a subtle alteration able to trigger neuronal network dysfunction, potentially involved in neurodegenerative processes [45-47]. The organotypic slice model represents a high-density cell system, where the 3D-architecture of specific resident cells, neuronal and non-neuronal, is preserved in a tissue culture setting $[15-17,48]$. The main finding of the current work is that local inflammation in organotypic spinal slices induced by CKs and LPS stimulations boosts network activity already after $4 \mathrm{H}$ treatments, as shown by the augmented PSCs and IPSCs frequency; however, only tissue reactivity brought about by CKs specifically reduced GABAergic current duration. We adopted short-term treatments to trigger inflammatory responses, without affecting neuronal membrane properties or inducing direct neurotoxicity, yet still able to alter synaptic transmission [17, 49].

The ability of CKs, directly, or of LPS-activated immune cells, indirectly, to increase synaptic activity or neuronal excitability has been previously described using several experimental settings and in different CNS structures [5, 17, $30,31,50,51]$. Yet, mechanistically, the influence on synaptic function of acute or prolonged exposures to inflammatory milieus has led often to controversial results, involving the glutamatergic signaling system $[6,52,53]$, or the inhibitory synaptic transmission [5, 30, 54], as well as neuronal excitability $[31,50,55]$, clearly indicating the complexity of the signaling pathways activated upon inflammation. In addition, the output readout used in these studies, i.e., post-synaptic currents, might be misleading, due to the variable amount of homeostatic plasticity taking place once destabilizing influences alter synaptic transmission [56]. Regardless the mechanisms leading to improved synaptic activity, only the direct exposure to CKs regulated the GABAergic current decay, probably via a post-synaptic mechanisms, as indicated by the detected changes in mIPSC's $\tau[26,57]$. The absence of LPS ability, even upon prolonged exposure of the slices, to regulate the inhibitory current decay was apparently not due to a lack of LPS activation of inflammation, a notion supported by the LPS-mediated increase in synaptic activity and by the cytokines and chemokines produced by LPS-treated slices, despite the low GFAP-positive cell reactivity and the changes in microglia morphology detected by immunocytochemistry, different to those reported in CKs. To note, the morphology of resident neuroglia together with the small increase in GFAP expression upon LPS treatment may indicate a different state of activation, supported by a different profile of CK network and production, providing an alternative (i.e., to CKs), inflammationmediated regulation of brain functions [35, 58]. LPS is experimentally used to mimic CNS bacterial inflammation [59], whereas CKs mimic the inflammatory network present when immune system intervenes in the CNS. These two functional conditions may affect synapses differently, and future investigations may allow elucidating CNS pathological conditions related to distinct etiologies. Indeed, we have to consider the diverse mechanisms of action triggered by CKs and LPS [60-63] which both act through precise receptors on microglia and neurons, affecting the microglia/ neuron communication and function [64].

CK regulation of GABAergic current in the absence of changes in GABA synthesis is thus a specific feature of the selected CK cocktail, able to mimic an inflammatory reaction involved in neuropathy $[2,6,17]$, and the mechanisms of this modulation might be a targetable pathway in spinal neuroinflammatory disease treatments.

We examined the main variables that might conceivably affect the kinetic properties of $\mathrm{GABA}_{\mathrm{A}} \mathrm{R}$ and therefore the GABAergic-PSC time course. First, we excluded the possibility of differences in the intracellular chloride concentration, brought about by neuroinflammation [38, 65] that could affect IPSC kinetics [66], as confirmed by our experiments where NKCC1 was pharmacologically blocked, leading to a shift in $\mathrm{Cl}^{-}$reversal potential. Our measurements show that the $\mathrm{Cl}^{-}$reversal potential was similar in the cultures treated by CKs or LPS, in the absence of bumetanide, yet CKs still induced a significant shortening of the GABAergic current duration. In bumetanide-treated cultures, the $\mathrm{Cl}^{-}$reversal potential differed from the predicted theoretical value. In our recording conditions, it is not possible to confirm a real shift in the internal chloride concentration as a result of the decreased influx $[41,42]$. However, the detected shifts in bumetanide are consistent with a $19 \mathrm{mM} \mathrm{Cl}^{-}$ intracellular concentration.

An alternative process that changes IPSC current duration in the CNS is the $\mathrm{GABA}_{\mathrm{A}} \mathrm{R} \alpha$-subunit composition [39, 67-69]. In particular, $\alpha 1$-subunit is responsible for fast deactivation, which results in faster-decaying currents [39, 69]. Our hypothesis, of an increased expression of $\alpha 1$-subunit upon CKs treatment, was supported by the efficacy of zolpidem [44] to prolong IPSC duration only in CK-treated slices. 
Our results describe for the first time a selective mechanism that could be triggered during inflammatory stress. In particular, under pathological conditions, the switch of $\mathrm{GABA}_{\mathrm{A}} \mathrm{R} \alpha 1$-subunit would induce faster $\mathrm{GABA}_{\mathrm{A}} \mathrm{R}$ decay time, weakening the IPSCs transmission. Therefore, lower IPSC duration could contribute to providing an aberrant excitatory transmission critical for pre-motor circuit tasks.

\section{Conclusions}

We exploited spinal cord explant cultures to investigate two diverse immune conditions in the CNS, characterized by different inflammatory networks and products, thus providing alternative inflammation-mediated regulation of the CNS functions. We have shown that these two functional conditions affect inhibitory synapses differently, and we hypothesized that the mechanisms of this modulation might be a targetable pathway in spinal neuroinflammatory disease treatments.

\section{Additional files}

Additional file 1: Table S1. Neuroglial cell reactivity upon 4-h treatments in CKs and LPS. (PDF $1613 \mathrm{~kb}$ )

Additional file 2: Figure S1. CKs and LPS increase sPSC frequency in organotypic slices A-B, Representative current tracings of sPSCs recorded in control (black) and after incubation in CKs (4 $\mathrm{H}$ in gray and $6 \mathrm{H}$ in blue; left) or in LPS (4H in gray and $6 \mathrm{H}$ in blue; right). C-D, Box plots summarize the increase in sPSC frequency $(20.3 \pm 9.5 \mathrm{~Hz}$ control; $27.9 \pm 9.4 \mathrm{~Hz} \mathrm{CKs} 4 \mathrm{H}$; $28.8 \pm 9.4 \mathrm{~Hz}$ CKs $6 \mathrm{H} ;{ }^{* * *} \mathrm{P}<0.001$ control vs CKs $4 \mathrm{H}$ and control vs CKs $6 \mathrm{H}$, one-way ANOVA) and in LPS (21.4 \pm 9.7 control; $28.4 \pm 10.4$ LPS $4 \mathrm{H}$; $33.3 \pm 9.8$ LPS $6 H_{;} * * *=0.008$ control vs LPS $4 H^{*} ; * * P<0.001$ control vs LPS $6 \mathrm{H}$, one-way ANOVA) treatments. (PDF $37 \mathrm{~kb}$ )

Additional file 3: Figure S2. CKs and LPS increase IPSC frequency in organotypic slices A-C. Box plots illustrate the mean value of IPSCS frequency (A), amplitude (B), and rise time (C) upon CK and LPS treatments. A significant increase was observed in the IPSC frequency at $\mathrm{CKs} 4 \mathrm{H}$ and $6 \mathrm{H}$, when compared to control $(3.3 \pm 1.5 \mathrm{~Hz}$ control; $4.7 \pm 1.9$ $\mathrm{Hz}$ CKs $4 \mathrm{H} ; 4.6 \pm 2.0 \mathrm{~Hz} C K s 6 \mathrm{H} ; n=40,33,37$, respectively; ${ }^{* *} P=0.003$ control vs $\mathrm{CKs} 4 \mathrm{H}$ and ${ }^{* *} P=0.006$ vs $\mathrm{CKs} 6 \mathrm{H}$, one-way ANOVA) and at LPS $4 \mathrm{H}$ and $6 \mathrm{H}$ when compared to their relative control $(1.7 \pm 0.9 \mathrm{~Hz}$ control; $3.1 \pm 2.6 \mathrm{~Hz}$ LPS $4 \mathrm{H} ; 3.4 \pm 2.7 \mathrm{~Hz}$ LPS $6 \mathrm{H} ; n=34,33,27$, respectively; ${ }^{*} P=0.002$, control vs LPS $4 \mathrm{H}$, and ${ }^{* *} P=0.001$ vs LPS $6 \mathrm{H}$, one-way ANOVA). IPSC amplitude (17.5 \pm 10.5 pA control; $19.4 \pm 9.1 \mathrm{pA}$ CKs $4 \mathrm{H}$; $17.0 \pm 11.2 \mathrm{pA} \mathrm{CKs} 6 \mathrm{H} ; 15.7 \pm 8.9 \mathrm{pA}$ control; $11.3 \pm 4.5 \mathrm{pA}$ LPS $4 \mathrm{H} ; 13.1 \pm$ $7.3 \mathrm{pA}$ LPS $6 \mathrm{H})$ and rise time $(2.5 \pm 0.8 \mathrm{~ms}$ control; $2.1 \pm 0.8 \mathrm{~ms}$ CKs $4 \mathrm{H}$; $2.6 \pm 1.4 \mathrm{~ms}$ CKs $6 \mathrm{H} ; 2.6 \pm 1.0 \mathrm{~ms}$ control; $2.5 \pm 1.0 \mathrm{~ms}$ LPS $4 \mathrm{H} ; 2.6 \pm 0.9 \mathrm{~ms}$ LPS $6 \mathrm{H}$ ) were unaffected by CK or LPS treatments. (PDF $6885 \mathrm{~kb}$ )

Additional file 4: Figure S3. GAD65/67 immunoreactivity in organotypic slices before and after CK or LPS treatments A and C. Representative images of spinal slices labeled for $\beta$-tubulin III (in blue) and GAD65/67 (in red) show GABAergic neurons in untreated (control) and $C K$ - and LPS-treated $(4 \mathrm{H}$ and $6 \mathrm{H})$ ventral area of spinal organotypic slices (14 DIV) B and D. Bar plots summarize the normalized GAD65/67 clusters (1483 \pm 62.2 control; $1503 \pm 49.9 \mathrm{CKs} 4 \mathrm{H} ; 1403 \pm 27.2 \mathrm{CKs} 6 \mathrm{H}$; $1295 \pm 45.3$ control; $1300 \pm 46.3$ LPS 4H; $1382 \pm 54.4$ LPS 6H) and the GAD65/67 intensity in a.u. (379.1 \pm 29.4 control; $423.9 \pm 40.8$ CKs $4 \mathrm{H}$; $383.9 \pm 38.5$ CKs $6 \mathrm{H} ; 417.3 \pm 46.9$ control; $391.3 \pm 58.4$ LPS 4H; $433.3 \pm 46.5$ LPS 6H). (PDF 28 kb)

Additional file 5: Figure S4 Spontaneous PSC and IPSC frequency in bumetanide $24 \mathrm{~h}$ before and after CKs $4 \mathrm{H}$. A Left, box plots of PSCs frequency values from control, bumetanide-treated slices prior and after CKs. Note the significant increase in PSC frequency BUM 24H and BUM
$24 \mathrm{H}+\mathrm{CKs} 4 \mathrm{H}$ compared to control $(24.4 \pm 7.8 \mathrm{~Hz}$ control; $37.1 \pm 11.4 \mathrm{~Hz}$ BUM 24H; $42.6 \pm 11.2 \mathrm{~Hz}$ BUM $24 \mathrm{H}+\mathrm{CKs} 4 \mathrm{H} ; n=9,10,9$, respectively; ${ }^{*} P=0.033$ control vs BUM $24 \mathrm{H} ; * * P=0.003$ control vs BUM $24 \mathrm{H}+\mathrm{CKs} 4 \mathrm{H}$ one-way ANOVA). Right, box plots of IPSCs frequency values upon BUM $24 \mathrm{H}$ and BUM $24 \mathrm{H}+\mathrm{CKs} 4 \mathrm{H}$ compared to control $(3.1 \pm 1.4 \mathrm{~Hz}$ control; $6.0 \pm 2.8 \mathrm{~Hz}$ BUM $24 \mathrm{H} ; 6.6 \pm 2.5 \mathrm{~Hz}$ BUM $24 \mathrm{H}+\mathrm{CKs} 4 \mathrm{H} ; n=10,11,10$, respectively; ${ }^{*} P=0.019$ control vs $B U M 24 \mathrm{H} ;{ }^{* *} P=0.005$ control vs BUM $24 \mathrm{H}+\mathrm{CKs} 4 \mathrm{H}$, one-way ANOVA). (PDF $278 \mathrm{~kb}$ )

Additional file 6: Figure S5. $\mathrm{E}_{\mathrm{GABA}}$ estimated in control, $\mathrm{CKs} 4 \mathrm{H}$ and LPS $4 \mathrm{H}$. IPSCS averaged and superimposed traces (top) recorded at different $V_{h}$ in control, CKs $4 \mathrm{H}$, and LPS $4 \mathrm{H}$. Bottom, IN curves were obtained by plotting GABA $A_{A}-P S C S$ mean amplitude against $V h$. Inset, note the similar $\left(E_{G A B A}\right)$ in all conditions. ${ }^{*} P<0.05,{ }^{* *} P<0.01$, one-way ANOVA. (PDF $13 \mathrm{~kb}$ )

\section{Abbreviations}

APV: (2R)-amino-5-phosphonovaleric acid; BSA: Bovine serum albumin; BUM: Bumetanide; CKs: Cytokines; CNQX: 6-Cyano-7-nitroquinoxaline-2,3dione; DH: Dorsal horn; DIV: Days in vitro; DRG: Dorsal root ganglia; FBS: Fetal bovine serum; GAD: Glutamate decarboxylase; GFAP: Glial fibrillary acidic protein; GM-CSF: Granulocyte-macrophage colony-stimulating factor; Iba1: Ionized calcium-binding adapter molecule 1; IL-1 $\beta$ : Interleukin-1beta; LPS: Lipopolysaccharide; MAP 2: Microtubule-associated protein 2; mPSCs: Miniature post-synaptic currents; PBS: Phosphate-buffered saline; PSCs: Post-synaptic currents; RT: Room temperature; SMI-32: Neurofilament H non-phosphorylated; TNF-a: Tumor-necrosis factor-alfa; TTX: Tetrodotoxin; $\mathrm{VH}$ : Ventral horn

\section{Acknowledgements}

The authors would like to thank M. Grandolfo for providing technical support with immunofluorescence labeling, confocal microscopy, and image analysis.

\section{Authors' contributions}

VG, GP, and MM performed the electrophysiology and immunohistochemistry experiments and analysis. VG contributed to the experimental design. EB and AA performed the Milliplex experiments and analysis. CB and LB conceived the study, design the experiments, interpreted the data, and wrote the manuscript. All authors read and approved the final manuscript.

\section{Funding}

We acknowledge the financial support from the European Union's Horizon 2020 research and innovation program under grant agreements No. 696656 and No. 785219 Graphene Flagship.

\section{Availability of data and materials}

The datasets supporting the conclusion of this article are included within the article (and its additional files). The datasets generated and/or analyzed during the current study are stored in a public repository and are available from the corresponding authors on reasonable request.

\section{Ethics approval and consent to participate}

All experiments were performed in accordance with the EU guidelines (2010/63/UE) and Italian law (Decree 26/14) and were approved by the local authority veterinary service and by our institution (SISSA) ethical committee. All efforts were made to minimize animal suffering and to reduce the number of animals used. Animal use was approved by the Italian Ministry of Health, in agreement with the EU Recommendation 2007/526/CE.

\section{Consent for publication}

Not applicable.

\section{Competing interests}

The authors declare that they have no competing interests.

\section{Author details}

${ }^{1}$ International School for Advanced Studies (SISSA/ISAS), 34136 Trieste, Italy. ${ }^{2}$ Department of Life Sciences, University of Trieste, 34127 Trieste, Italy. ${ }^{3}$ Department NEUROFARBA, University of Florence, 50139 Florence, Italy. ${ }^{4}$ Dipartimento di Medicina Sperimentale e Clinica, University of Florence, 
50139 Florence, Italy. ${ }^{5}$ Present address: Wolfson Centre for Age Related Disease, King's College London, Guy's Campus, London SE1 1UL, UK.

\section{Received: 15 February 2019 Accepted: 11 June 2019} Published online: 25 June 2019

\section{References}

1. Chen WW, Zhang X, Huang WJ. Role of neuroinflammation in neurodegenerative diseases (review). Mol Med Rep. 2016;13:3391-6.

2. Mandolesi G, Gentile A, Musella A, Fresegna D, De Vito F, Bullitta S, Sepman H, Marfia GA, Centonze D. Synaptopathy connects inflammation and neurodegeneration in multiple sclerosis. Nat Rev Neurol. 2015;11:711-24.

3. Pozzi D, Menna E, Canzi A, Desiato G, Mantovani C, Matteoli M. The communication between the immune and nervous systems: the role of IL-1 $\beta$ in synaptopathies. Front Mol Neurosci. 2018;11:111.

4. Musella A, Gentile A, Rizzo FR, De Vito F, Fresegna D, Bullitta S, Vanni V, Guadalupi L, Stampanoni Bassi M, Buttari F, Centonze D, Mandolesi G. Interplay between age and neuroinflammation in multiple sclerosis: effects on motor and cognitive functions. Front Aging Neurosci. 2018;10:238.

5. Kawasaki Y, Zhang L, Cheng JK, Ji RR. Cytokine mechanisms of central sensitization: distinct and overlapping role of interleukin-1 beta, interleukin-6, and tumor necrosis factor-alpha in regulating synaptic and neuronal activity in the superficial spinal cord. J Neurosci. 2008;28:5189-94.

6. Centonze D, Muzio L, Rossi S, Cavasinni F, De Chiara V, Bergami A, Musella A, D'Amelio M, Cavallucci V, Martorana A, Bergamaschi A, Cencioni MT, Diamantini A, Butti E, Comi G, Bernardi G, Cecconi F, Battistini L, Furlan R, Martino G. Inflammation triggers synaptic alteration and degeneration in experimental autoimmune encephalomyelitis. J Neurosci. 2009;29:3442-52.

7. Glass CK, Saijo K, Winner B, Marchetto MC, Gage FH. Mechanisms underlying inflammation in neurodegeneration. Cell. 2010;140:918-34.

8. Hellstrom IC, Danik M, Luheshi GN, Williams S. Chronic LPS exposure produces changes in intrinsic membrane properties and a sustained ILbeta-dependent increase in GABAergic inhibition in hippocampal CA1 pyramidal neurons. Hippocampus. 2005;15:656-64.

9. Viviani B, Bartesaghi S, Gardoni F, Vezzani A, Behrens MM, Bartfai T, Binaglia M, Corsini E, Di Luca M, Galli CL, Marinovich M. Interleukin- 1beta enhances NMDA receptor-mediated intracellular calcium increase through activation of the Src family of kinases. J Neurosci. 2003;23:8692e8700.

10. Murray CA, McGahon B, McBennett S, Lynch MA. Interleukin-1 beta inhibits glutamate release in hippocampus of young, but not aged, rats, Neurobiol Aging. 1997;18:343-8.

11. Zeise ML, Espinoza J, Morales P, Nalli A. Interleukin-1 beta does not increase synaptic inhibition in hippocampal CA3 pyramidal and dentate gyrus granule cells of the rat in vitro. Brain Res. 1997;768:341-4.

12. Wang $S$, Cheng $Q$, Malik $S$, Yang J. Interleukin-1 $\beta$ inhibits $\gamma$ aminobutyric acid type a (GABAA) receptor current in cultured hippocampal neurons. JPet. 2000;292:497-504.

13. Luk WP, Zhang Y, White TD, Lue FA, Wu C, Jiang CG, Zhang L, Moldofsky H. Adenosine: a mediator of interleukin-1 beta-induced hippocampal synaptic inhibition. J Neurosci. 1999;19:4238-44.

14. Ikegaya Y, Delcroix I, Iwakura Y, Matsuki N, Nishiyama N. Interleukin1 beta abrogates long-term depression of hippocampal CA1 synaptic transmission. Synapse. 2003:47:54-7.

15. Avossa D, Rosato-Siri MD, Mazzarol F, Ballerini L. Spinal circuits formation: a study of developmentally regulated markers in organotypic cultures of embryonic mouse spinal cord. Neuroscience. 2003;122:391-405.

16. Furlan F, Taccola G, Grandolfo M, Guasti L, Arcangeli A, Nistri A, et al. ERG conductance expression modulates the excitability of ventral horn GABAergic interneurons that control rhythmic oscillations in the developing mouse spinal cord. J Neurosci. 2007:27:919-28.

17. Medelin M, Giacco V, Aldinucci A, Castronovo G, Bonechi E, Sibilla A, et al. Neuro-immune crosstalk in organotypic spinal slices: investigating the protective role of an NGF-mimetic. Molecular Brain. 2018;11:3.

18. Kiehn O, Hounsgaard J, Sillar KT. Basic building blocks of vertebrate spinal central pattern generators. In: Stein PSG, et al., editors. Neurons, networks and motor behaviour. Cambridge: The MIT Press; 1997. p. 47-59.

19. Li X, Tupper JC, Bannerman DD, Winn RK, Rhodes CJ, Harlan JM. Phosphoinositide 3 kinase mediates Toll-like receptor 4-induced activation of NF-kappa B in endothelial cells. Infect Immun. 2003;71:4414-20.
20. Vereker E, Campbell V, Roche E, McEntee E, Lynch MA. Lipopolysaccharide inhibits long term potentiation in the rat dentate gyrus by activating caspase-1. J Biol Chem. 2000;275:26252-8.

21. Usmani S, Aurand ER, Medelin M, Fabbro A, Scaini D, Laishram J, et al. 3D meshes of carbon nanotubes guide functional reconnection of segregated spinal explants. Sci Adv. 2016;2:e1600087.

22. Ifergan I, Davidson TS, Kebir H, Xu D, Palacios-Macapagal D, Cann J, Rodgers JM, Hunter ZN, Pittet CL, Beddow S, Jones CA, Prat A, Sleeman MA, Miller SD. Targeting the GM-CSF receptor for the treatment of CNS autoimmunity. J Autoimmun. 2017:84:1-11.

23. Hanisch UK. Microglia as a source and target of cytokines. Glia. 2002; 40:140-55.

24. Dzhala VI, Talos DM, Sdrulla DA, Brumback AC, Mathews GC, Benke TA, Delpire E, Jensen FE, Staley KJ. NKCC1 transporter facilitates seizures in the developing brain. Nat Med. 2005;11:1205-13 Epub 2005 Oct 9.

25. Caldeira C, Oliveira AF, Cunha C, Vaz AR, Falcão AS, Fernandes A, Brites D. Microglia change from a reactive to an age-like phenotype with the time in culture. Front Cell Neurosci. 2014;2(8):152.

26. Medelin M, Rancic V, Cellot G, Laishram J, Veeraraghavan P, Rossi C, et al. Altered development in GABA co-release shapes glycinergic synaptic currents in cultured spinal slices of the SOD1G93A mouse model of ALS. J Physiol. 2016;594:3827-40.

27. Galante M, Nistri A, Ballerini L. Opposite changes in synaptic activity of organotypic rat spinal cord cultures after chronic block of AMPA/kainate or glycine and GABAA receptors. J Physiol. 2000;523(Pt 3):639-51.

28. Maric D, Maric I, Wen X, Fritschy JM, Sieghart W, Barker JL, Serafini R. GABAA receptor subunit composition and functional properties of $\mathrm{Cl}$ - channels with differential sensitivity to zolpidem in embryonic rat hippocampal cells. J Neurosci. 1999;15(19):4921-37.

29. Chen L, Savio Chan C, Yung WH. Electrophysiological and behavioral effects of zolpidem in rat globus pallidus. Exp Neurol. 2004;186:212-20.

30. Zhang $H$, Dougherty PM. Acute inhibition of signalling phenotype of spinal GABAergic neurons by tumour necrosis factor-alpha. J Physiol. 2011;589:4511-26.

31. Zhang H, Nei H, Dougherty PM. A p38 mitogen-activated protein kinasedependent mechanism of disinhibition in spinal synaptic transmission induced by tumor necrosis factor-a. J Neurosci. 2010;30:12844-55.

32. Liu Q, Wong-Riley MTT. Developmental changes in the expression of GABAA receptor subunits $a 1, a 2$, and $a 3$ in the rat pre-Bötzinger complex. J Appl Physiol. 2004;10:1152.

33. Pribiag H, Stellwagen D. TNF-a downregulates inhibitory neurotransmission through protein phosphatase 1-dependent trafficking of GABA(A) receptors. J Neurosci. 2013;33:15879-93.

34. Puram SV, Riccio A, Koirala S, Ikeuchi Y, Kim AH, Corfas G, Bonni A. A TRPC5regulated calcium signaling pathway controls dendrite patterning in the mammalian brain. Genes Dev. 2011;25:2659-73.

35. Mathieu P, Battista D, Depino A, Roca V, Graciarena M, Pitossi F. The more you have, the less you get: the functional role of inflammation on neuronal differentiation of endogenous and transplanted neural stem cells in the adult brain. J Neurochem. 2010;112:1368-85.

36. Rahimifard M, Maqbool F, Moeini-Nodeh S, Niaz K, Abdollahi M, Braidy N, Nabavi SM, Nabavi SF. Targeting the TLR4 signaling pathway by polyphenols: a novel therapeutic strategy for neuroinflammation. Ageing Res Rev. 2017;36:11-9.

37. Schäfers M, Sorkin L. Effect of cytokines on neuronal excitability. Neurosci Lett. 2008:437:188-93.

38. Funk K, Woitecki A, Franjic-Würtz C, Gensch T, Möhrlen F, Frings S Modulation of chloride homeostasis by inflammatory mediators in dorsal root ganglion neurons. Mol Pain. 2008:4:32.

39. Moroni M, Meyer JO, Lahmann C, Sivilotti LG. In glycine and GABA(A) channels, different subunits contribute asymmetrically to channel conductance via residues in the extracellular domain. J Biol Chem. 2011;286:13414-22.

40. Ben-Ari Y. NKCC1 chloride importer antagonists attenuate many neurological and psychiatric disorders. Trends Neurosci. 2017:40:536-54.

41. DeFazio RA, Keros S, Quick MW, Hablitz JJ. Potassium-coupled chloride cotransport controls intracellular chloride in rat neocortical pyramidal neurons. J Neurosci. 2000;20:8069-76.

42. Ostroumov A, Simonetti M, Nistri A. Cystic fibrosis transmembrane conductance regulator modulates synaptic chloride homeostasis in motoneurons of the rat spinal cord during neonatal development. Dev Neurobiol. 2011;71:253-68. 
43. Vicini S, Ferguson C, Prybylowski K, Kralic J, Morrow AL, Homanics GE. GABA(A) receptor alpha1 subunit deletion prevents developmental changes of inhibitory synaptic currents in cerebellar neurons. J Neurosci. 2001:21:3009-16.

44. Perrais D, Ropert N. Effect of zolpidem on miniature IPSCs and occupancy of postsynaptic GABAA receptors in central synapses. J Neurosci. 1999;19:578-88.

45. Ransohoff RM. How neuroinflammation contributes to neurodegeneration Science. 2016;353:777-83.

46. Giovannetti EA, Fuhrmann M. Unsupervised excitation: GABAergic dysfunctions in Alzheimer's disease. Brain Res. 2019;1707:216-26.

47. Liberman AC, Trias E, da Silva Chagas L, Trindade P, Dos Santos Pereira M, Refojo D, Hedin-Pereira C, Serfaty CA. Neuroimmune and inflammatory signals in complex disorders of the central nervous system. Neuroimmunomodulation. 2018;25:246-70.

48. Masuch A, Shieh CH, van Rooijen N, van Calker D, Biber K. Mechanism of microglia neuroprotection: involvement of P2X7, TNFa, and valproic acid. Glia. 2016;64:76-89.

49. Pascual O, Ben Achour S, Rostaing P, Triller A, Bessis A. Microglia activation triggers astrocyte-mediated modulation of excitatory neurotransmission. Proc Natl Acad Sci U S A. 2012;109:E197-205.

50. Gao F, Liu Z, Ren W, Jiang W. Acute lipopolysaccharide exposure facilitates epileptiform activity via enhanced excitatory synaptic transmission and neuronal excitability in vitro. Neuropsychiatr Dis Treat. 2014;10:1489-95.

51. Igelhorst BA, Niederkinkhaus $V$, Karus C, Lange MD, Dietzel ID. Regulation of neuronal excitability by release of proteins from glial cells. Philos Trans $R$ Soc Lond Ser B Biol Sci. 2015;370(1672).

52. Centonze D, Muzio L, Rossi S, Furlan R, Bernardi G, Martino G. The link between inflammation, synaptic transmission and neurodegeneration in multiple sclerosis. Cell Death Differ. 2010;17:1083-91.

53. Rossi S, Furlan R, De Chiara V, Motta C, Studer V, Mori F, Musella A, Bergami A, Muzio L, Bernardi G, Battistini L, Martino G, Centonze D. Interleukin-1 $\beta$ causes synaptic hyperexcitability in multiple sclerosis. Ann Neurol. 2012;71:76-83.

54. Rossi S, Muzio L, De Chiara V, Grasselli G, Musella A, Musumeci G, Mandolesi G, De Ceglia R, Maida S, Biffi E, Pedrocchi A, Menegon A, Bernardi G, Furlan R, Martino G, Centonze D. Impaired striatal GABA transmission in experimental autoimmune encephalomyelitis. Brain Behav Immun. 2011;25:947-56.

55. Zhou Y, Tang H, Liu J, Dong J, Xiong H. Chemokine CCL2 modulation of neuronal excitability and synaptic transmission in rat hippocampal slices. J Neurochem Volume. 2010;116:406-14.

56. Turrigiano G. Homeostatic synaptic plasticity: local and global mechanisms for stabilizing neuronal function. Cold Spring Harb Perspect Biol. 2012;4:a005736.

57. Balakrishnan V, Kuo SP, Roberts PD, Trussell LO. Slow glycinergic transmission mediated by transmitter pooling. Nat Neurosci. 2009;12:286-94.

58. Letournel-Boulland ML, Fages C, Rolland B, Tardy M. Lipopolysaccharides (LPS), up-regulate the IL-1-mRNA and down-regulate the glial fibrillary acidic protein (GFAP) and glutamine synthetase (GS)-mRNAs in astroglial primary cultures. Eur Cytokine Netw. 1994;5:51-6.

59. Kuhn SA, van Landeghem FK, Zacharias R, Färber K, Rappert A, Pavlovic S, Hoffmann A, Nolte C, Kettenmann H. Microglia express GABA(B) receptors to modulate interleukin release. Mol Cell Neurosci. 2004;25:312-22.

60. Pocock JM, Kettenmann H. Neurotransmitter receptors on microglia. Trends Neurosci. 2007;30:527-35.

61. Fogal B, Hewett SJ. Interleukin-1 beta: a bridge between inflammation and excitotoxicity? J Neurochem. 2008;106:1-23.

62. Probert L. TNF and its receptors in the CNS: the essential, the desirable and the deleterious effects. Neuroscience. 2015;302:2-22.

63. Becher B, Tugues S, Greter M. GM-CSF: from growth factor to central mediator of tissue inflammation. Immunity. 2016;45:963-73.

64. Szepesi Z, Manouchehrian O, Bachiller S, Deierborg T. Bidirectional microglia-neuron communication in health and disease. Front Cell Neurosci. 2018;12:323.

65. Coull JAM. Trans-synaptic shift in anion gradient in spinal lamina I neurons as a mechanism of neuropathic pain. Nature. 2003;424:938-42.

66. Houston CM, Bright DP, Sivilotti LG, Beato M, Smart TG. Intracellular chloride ions regulate the time course of GABA-mediated inhibitory synaptic transmission. J Neurosci. 2009;29:10416-23.
67. Dunning DD, Hoover CL, Soltesz I, Smith MA, O'Dowd DK. GABA(A) receptor-mediated miniature postsynaptic currents and alpha-subunit expression in developing cortical neurons. J Neurophysiol. 1999;82:3286-97.

68. Hutcheon B, Morley P, Poulter MO. Developmental change in GABAA receptor desensitization kinetics and its role in synapse function in rat cortical neurons. J Physiol. 2000;522:3-17.

69. Dixon C, Sah P, Lynch JW, Keramidas A. GABAA receptor $a$ and $\gamma$ subunits shape synaptic currents via different mechanisms. J Biol Chem. 2014;289:5399-411.

\section{Publisher's Note}

Springer Nature remains neutral with regard to jurisdictional claims in published maps and institutional affiliations.

\section{Ready to submit your research? Choose BMC and benefit from:}

- fast, convenient online submission

- thorough peer review by experienced researchers in your field

- rapid publication on acceptance

- support for research data, including large and complex data types

- gold Open Access which fosters wider collaboration and increased citations

- maximum visibility for your research: over $100 \mathrm{M}$ website views per year

At BMC, research is always in progress.

Learn more biomedcentral.com/submissions 